\title{
Correction to: Relationship Between Magnetic Resonance T2-Mapping and Matrix Metalloproteinase 1,3 in Knee Osteoarthritis
}

\author{
Lei Shi ${ }^{1} \cdot$ Kexin Wang ${ }^{1} \cdot$ Jinghong $\mathrm{Yu}^{1} \cdot$ Mingkai $\mathrm{Li}^{1} \cdot$ Guangmei Men ${ }^{1} \cdot$ Gang $\mathrm{Ma}^{2} \cdot \mathrm{Xing} \mathrm{Wang}^{3}$
}

Published online: 19 April 2021

(c) The Author(s) 2021

\section{Correction to: Indian Journal of Orthopaedics https://doi.org/10.1007/s43465-020-00293-2}

The original version of this article unfortunately contained some mistakes. Some figures were incorrect and interchanged respectively. The correct assignment of figures is as follows: Figs. 2, 4 and 6 were replaced by new figures. The previous Fig. 2 in the article is actually Fig. 3, the previous Fig. 3 in the article is actually Fig. 5, and the previous Fig. 5 was deleted. In addition, reference [3] was presented incorrectly. The correct figures and reference are given below.

The original article has been corrected.

1 Radiology Department, The Second Affiliated Hospital of Inner Mongolia Medical University, Hohhot 010020, Inner Mongolia, China

2 Joint Surgery, The Second Affiliated Hospital of Inner Mongolia Medical University, Hohhot 010020, Inner Mongolia, China

3 School of Basic Medicine, Inner Mongolia Medical University, Hohhot 010010, Inner Mongolia, China 

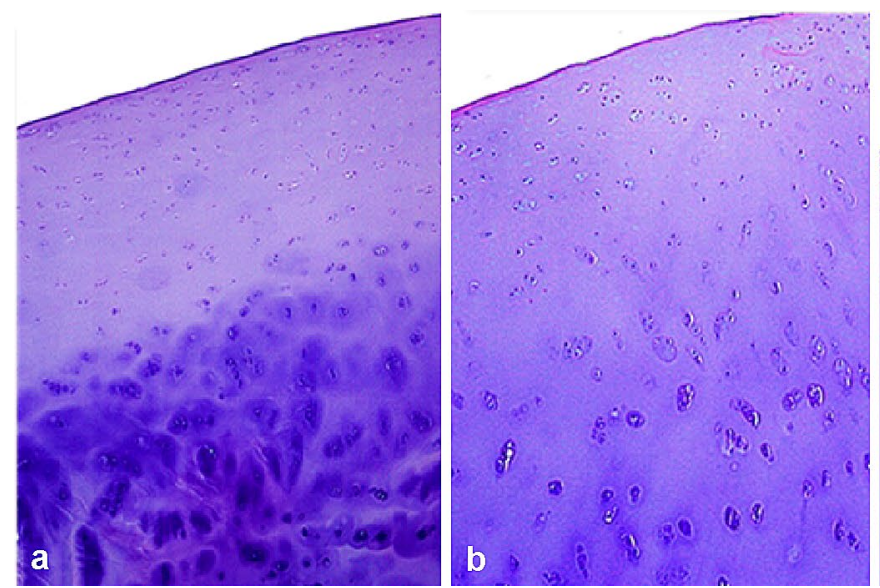

Fig. 2 Pathological grade of knee joint cartilage he $(\times 100)$. Grade I-IV degeneration of the cartilage of the knee joint: the chondrocyte matrix is unevenly stained and the chondrocytes are disordered; the cartilage surface is rough, the normal structure of the cartilage
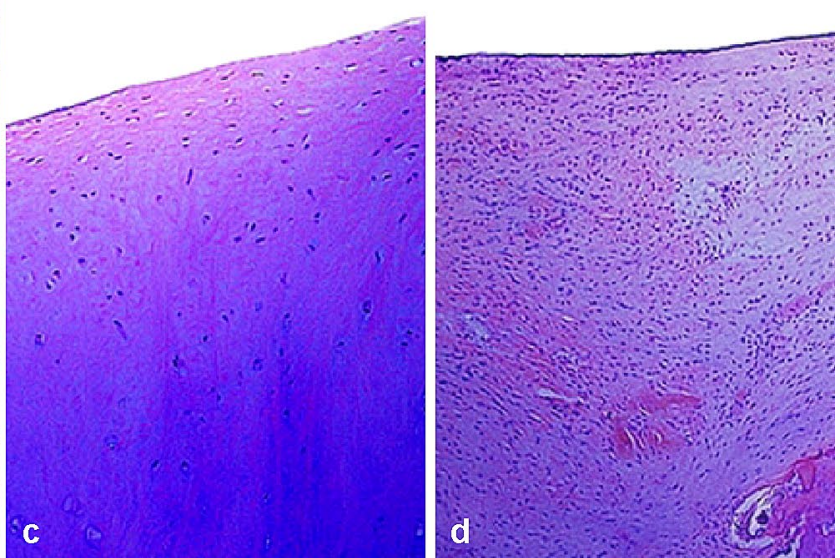

surface is destroyed, and the matrix is unevenly stained; the chondrocytes are suddenly reduced and the structure is disordered; obviously the cartilage structure was damaged and the chondrocytes were necrotic
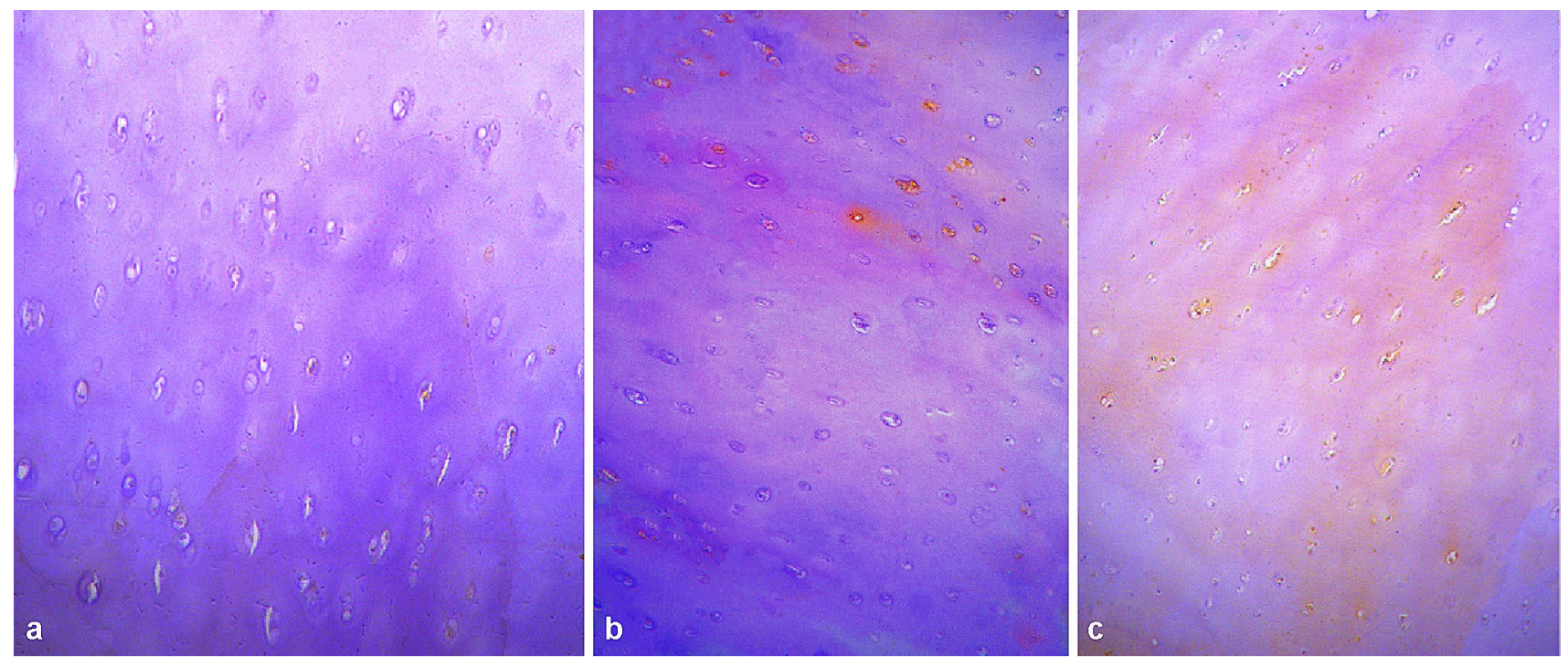

Fig. 3 MMP-1 immunohistochemical staining of knee cartilage $(\times 100)$. With the increase of knee cartilage degeneration, brown cells increased and the expression of MMP-1 increased significantly 


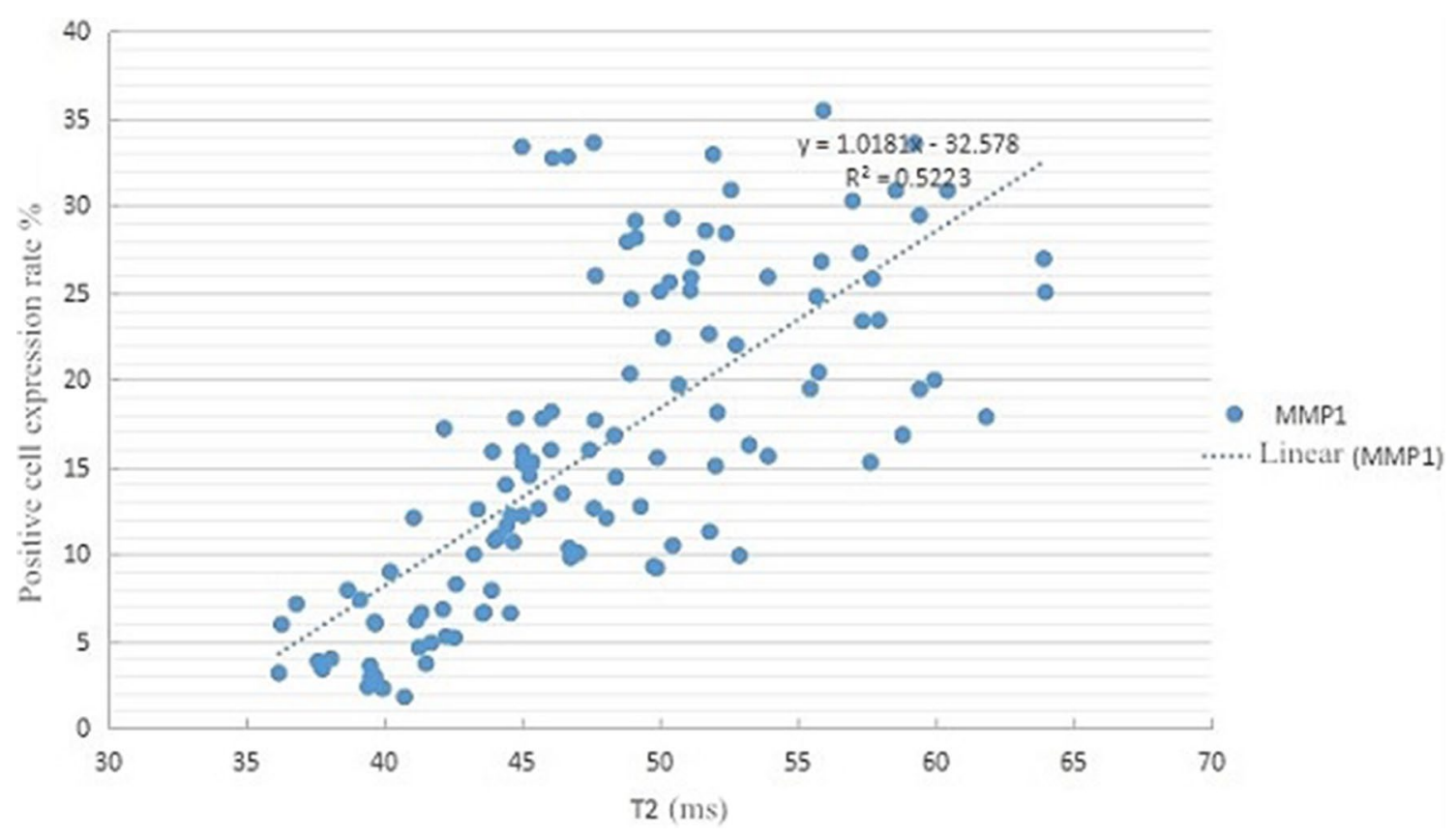

Fig. 4 Scatter plot of T2 value and MMP1 expression in OA knee articular cartilage
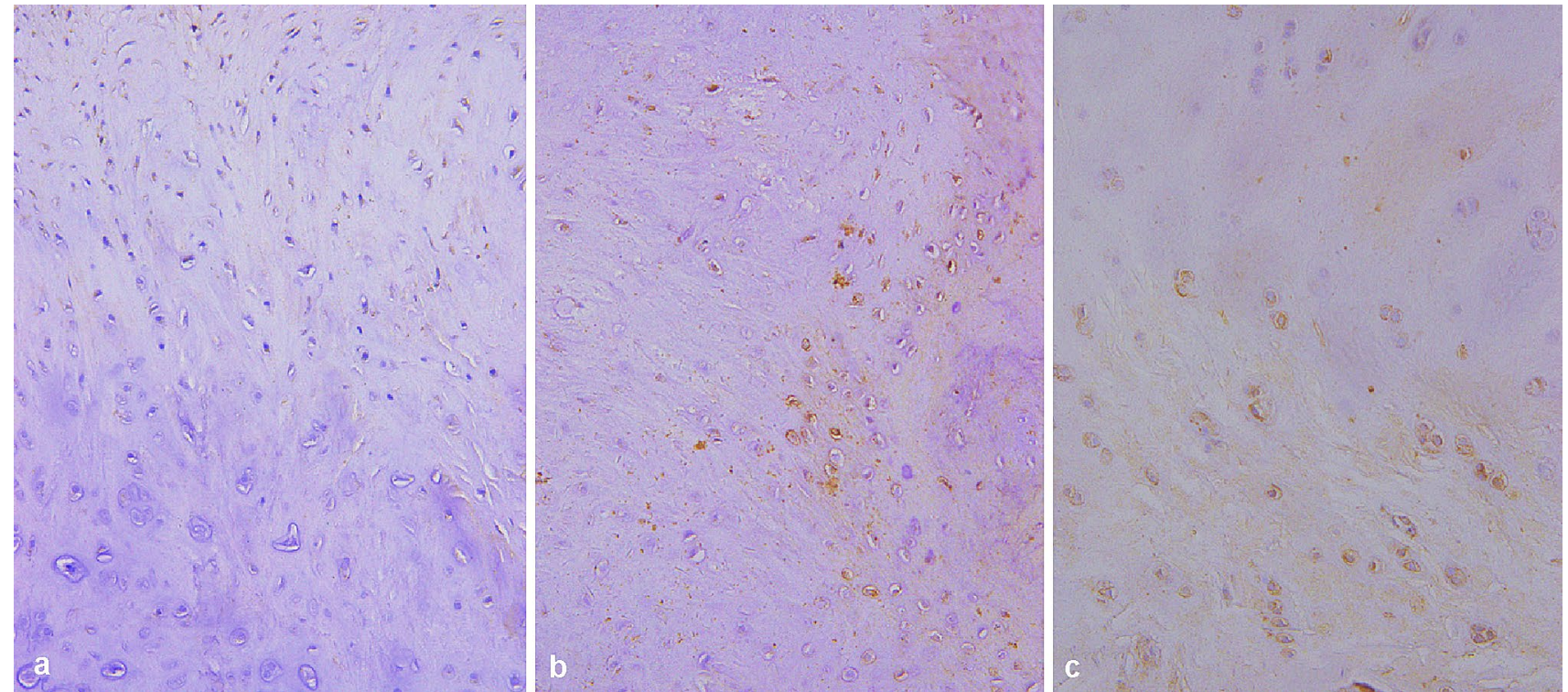

Fig. 5 MMP-3 immunohistochemical staining of knee cartilage $(\times 100)$. The expression of MMP-3 increased with the degree of degeneration of cartilage in the knee joint, and it was found that the expression of MMP-3 was higher in the lower and deep layers of cartilage 


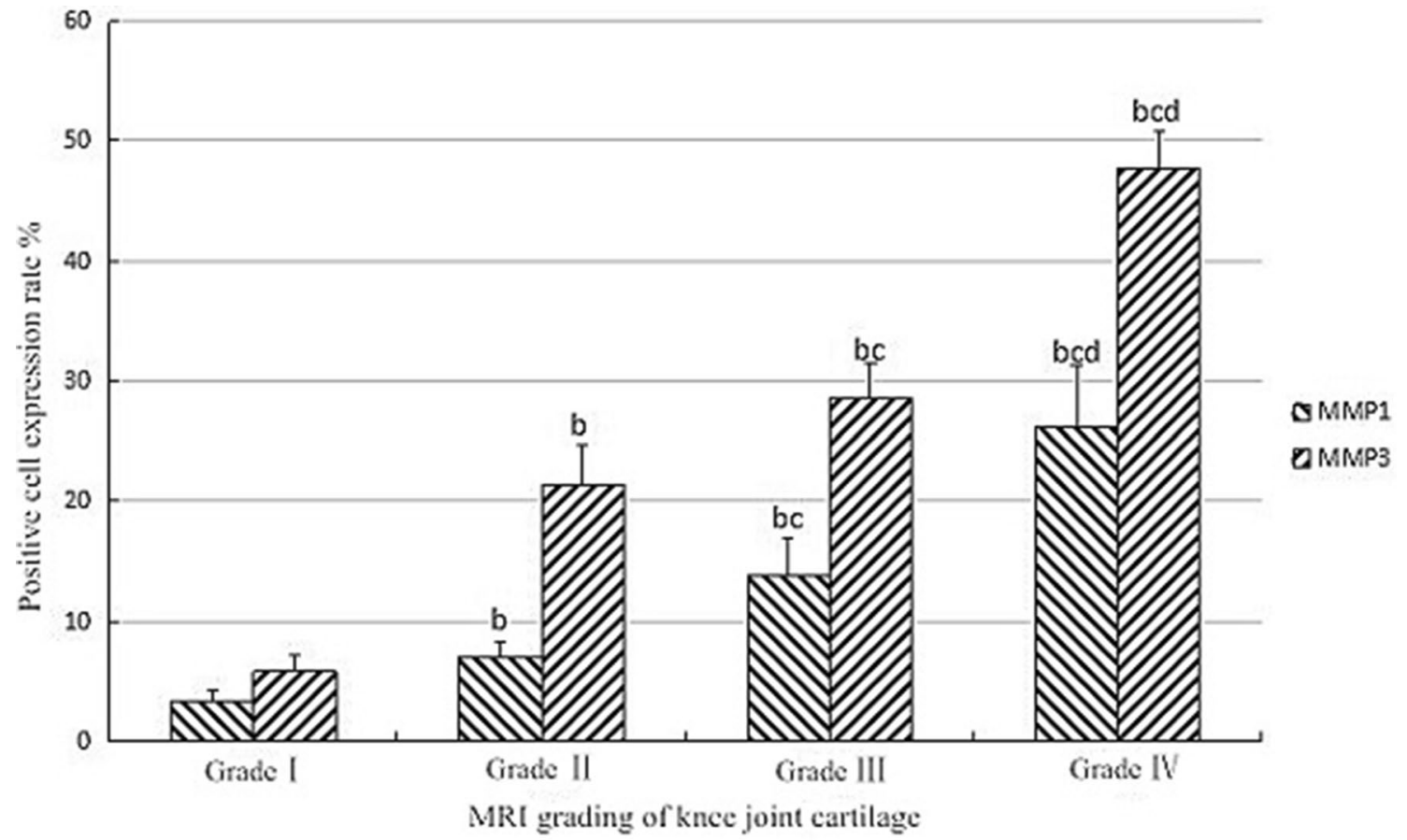

Fig. 6 The expression of MMP1, MMP3 in various grades. The comparison between $\mathrm{b}$ and grade $\mathrm{I}, P<0.05$, The comparison between $\mathrm{c}$ and grade II, $P<0.05$, The com-parison between $\mathrm{d}$ and grade III, $P<0.05$

Open Access This article is licensed under a Creative Commons Attribution 4.0 International License, which permits use, sharing, adaptation, distribution and reproduction in any medium or format, as long as you give appropriate credit to the original author(s) and the source, provide a link to the Creative Commons licence, and indicate if changes were made. The images or other third party material in this article are included in the article's Creative Commons licence, unless indicated otherwise in a credit line to the material. If material is not included in the article's Creative Commons licence and your intended use is not permitted by statutory regulation or exceeds the permitted use, you will need to obtain permission directly from the copyright holder. To view a copy of this licence, visit http://creativecommons.org/licenses/by/4.0/.

\section{Reference}

3. Chen, D., Shen, J., Zhao, W., et al. (2017). Osteoarthritis: toward a comprehensive understanding of pathological mechanism. Bone Res 5, 16044. 